\title{
Hybrid Hierarchical Architecture for Integration and Interoperability of a One-Stop E-Government Portal
}

\author{
Khairul Anwar Sedek ${ }^{1}$, Mohd Adib Omar ${ }^{2}$, Shahida Sulaiman ${ }^{3}$, Mohd Nizam Osman ${ }^{4}$ \\ ${ }^{1,4}$ Faculty of Computer and Mathematical Sciences, Universiti Teknologi MARA Perlis Branch, Malaysia \\ ${ }^{2}$ School of Computer Sciences, Universiti Sains Malaysia, Pulau Pinang, Malaysia. \\ ${ }^{3}$ Department of Software Engineering, Faculty of Computing, Universiti Teknologi Malaysia, Johor, \\ Malaysia \\ Corresponding author:*khairulanwarsedek@uitm.edu.my \\ Received Date: 31 August 2018 \\ Accepted Date: 12 November 2018
}

\begin{abstract}
The main function of a one-stop e-government portal is to provide single access point to various egovernment services for its users. It needs an effective architecture for integration and interoperability between a one-stop e-government portal and related e-government services. However, due to heterogeneous e-government service platforms and bad e-government service organization, a one-stop egovernment portal may fail to provide its main function effectively. This study proposes an architectural approach to improve integration and interoperability among one-stop e-government portal, e-government applications, and e-government services using a service component architecture. The evaluation shows that the proposed approach could be successfully implemented in a prototype of a one-stop e-government portal.
\end{abstract}

Keywords: E-Government; Integration; Interoperability; Hierarchical Architecture

\section{INTRODUCTION}

The main function of a one-stop e-government portal is to provide or enhance public services or managing government services in a single access point (Novakouski \& Lewis, 2012). However, it needs an effective architecture for integration and interoperability between one-stop e-government portal and e-government services. In Malaysian Public Sector ICT Strategic Plan 2016-2020, having integrated digital services is one of the important strategic initiatives to strengthen the one-stop digital services ("The Malaysian Public Sector ICT Strategic Plan 2016 - 2020,” 2016).

Nevertheless, a one-stop e-government portal has been found ineffective in providing single access point e-government services to users due to the following issues:

- Addressing integration and interoperability issues (As'ad, Khazaei, Akhgar, \& Alqatawna, 2016; Markande, 2011; Goldkuhl, 2008; Wimmer, 2002)

- Redundancy of services (Cellary \& Strykowski, 2009; Tambouris, 2001)

- Determining architectural approach that can be adopted by e-government project (Fishenden \& Thompson, 2013; Ahuja \& Ahuja, 2008)

- Building trust among department and agencies that provide and share services to each other (UN, 2012)

Therefore, this study proposes an architectural approach to improve integration and interoperability among one-stop e-government portal, e-government applications, and e-government services using a service component architecture. The approach is evaluated using a prototype implementation, expert review, and 
portal comparison. It was successfully implemented in a prototype implementation of one-stop egovernment portal.

As the proof of concept, this study evaluates the proposed approach by creating the prototype of a one-stop e-government portal and comparing it with MyGovernment portal, the official Malaysian one-stop egovernment portal. The comparison aims to investigate the level of integration between a one-stop egovernment portal and an existing e-government system in order to provide more benefits to users and egovernment providers.

This paper is organized into six sections. Section II presents the related work, followed by Section III elaborates the proposed approach that is the hierarchical architecture for integration and interoperability of a one-stop e-government portal. Section IV reports the prototype evaluation as the proof of concept. Section $\mathrm{V}$ provides the discussion and finally the conclusion in Section VI.

\section{Related Works}

Malaysia has developed standards, reference model and framework but architecture based initiative was not found which can lead to lack of e-government development although architecture is important initiative especially for one-stop e-government portal development (Fath-Allah, Cheikhi, Al-Qutaish, \& Idri, 2014). Therefore, this study proposes a holistic solution to improve e-government integration and interoperability for one-stop e-government portal through e-government architecture approach which fulfil architectural requirements and principles.

E-government architecture identifies the standard, infrastructure components, applications, technologies, business model, and guidelines to facilitates the collaboration between organizations (Ebrahim \& Irani, 2005). Thus, the architecture should have integration and interoperability for e-government system collaboration, enterprise workflow for work collaboration and application composition for e-government application development. These three elements provide comprehensive approach to build architectural approach for integration and interoperability of one-stop e-government portal. The main aim is to facilitate integration and interoperability among e-government systems that involve public service collaboration. To fulfil this aim, the solution should overcome interoperability and integration issue and workflow coordination between e-government services.

Distributed architecture using Service Oriented Architecture (SOA) is widely used as integration method between e-government system based on Simple Object Access Protocol (SOAP) (Dutta, Devi, \& Arora, 2017; Chaabane, Hadouaj, \& Ghédira, 2015; Widodo, Istiyanto, Wardoyo, \& Santoso, 2013; Votis, Alexakos, Vassiliadis, \& Likothanassis, 2008). Paul (2015) uses Service Component Architecture (SCA) to create composite application for integration with other services using multiple languages, multiple container technologies, and multiple access methods. SCA is one of the integration approaches that can be used by e-government architecture as an alternative for other approaches such as Government Service Bus (GSB) (Widodo et al., 2013; Yan \& Guo, 2010) and Government Modelling Language (GML) (Tambouris, Archetypon, \& Wimmer, 2004). Widodo et al. (2013) use GSB based on Java Business Integration (JBI) as a middleware which is different from SCA approach.

SCA approach hides middleware approach using a composite application. It provides data access from multiple location and multiple format using SCA components reference and provides an application as a service for any other systems. Thus, SCA simplifies composite application assemblies from integration and interoperability with heterogeneous Application Programming Interface (APIs) and data formats both as service providers and service consumers. 
Layered-architecture mostly based on technology stack that has been used in each layer (Lankhorst \& Derks, 2007; Salhofer \& Ferbas, 2007; Ebrahim \& Irani, 2005). For example, Salhofer and Ferbas (2007) propose a three-layer architecture that consists of interface layer, business functional layer, and transaction layer. Layered architecture provides technology flexibility that allows technology changes at any layer. Additionally, layered architecture provides flexibility to choose different technology in each layer. For example, at the process layer developers can choose between Java class or BPEL as the implementation language.

Widodo (2010) proposes layered e-government architecture based on organizational structure organized by e-government providers according to public service administration structure that consists of "national" at the top level, "provinces" at the second level and "district" or "city" at the lowest level. This structure can be adapted in a country to suit specific administration structure. For example, Malaysia's public administration structure comprises Prime Minister's Office at the top level and ministries and states at the second level. Each ministry has its own departments. It eases coordination of interoperability from higher province level to it sub-ordinates at a district or a city level.

In an e-government system, workflow is an important feature that should be addressed to ensure a smooth service operation including internal and external processes to support work collaboration among agencies. However, only a few works adapt workflow for e-government processes using different methods such WfMS (Beer, Kunis, \& Runger, 2006), Agent-based Workflow (Verginadis, Gouvas, \& Mentzas, 2005), and BPEL4WS (De Angelis, 2009; Contenti, Mecella, Termini, \& Baldoni, 2005). SCA supports business process implementation in its component implementation using BPEL, Java or Ruby (Laws, Combellack, Feng, Mahbod, \& Nash, 2011). However, there is no work that utilizes this feature to implement business process of an e-government workflow. Hence, it would be more significant to utilize SCA implementation to ease workflow and interoperability with external services.

Based on thorough review of each approach, the study adopts and customises a few approaches that are useful to be adopted for integration and interoperability of one-stop e-government portal. In addition, Widodo's (2010) organizational structure approach can be adapted to Malaysia's public administration structure. While, SCA approach is useful for integration and interoperability in heterogeneous service interface between a one-stop e-government portal and its service providers together with an e-government workflow using an enterprise operational process (Gong \& Janssen, 2013) which has never been experimented in an e-government architecture.

\section{THE PROPOSED ARCHITECTURE}

The proposed approach includes One-Stop E-Government Portal (1EGP) that has the main role to provide the interface for end-users to access all services in a single portal. To fulfil this role, there are important functions that need to be considered carefully:

- Provide a one-stop centre to e-government applications for end-users of the portal

- Provide the hosting of an e-government application in the portal

- Integrate all e-government applications or systems across government agencies

- Provide a service management for end-users and portal administrator

Figure 1 depicts the architecture for integration and interoperability of 1EGP, E-Government Application (EGA), and E-Government Services (EGS). The architectural approach has two main characteristics: hierarchical and hybrid architecture. 
The hierarchical architecture organizes 1EGP, EGP, and EGS in hierarchical structure according to public administration structure. This is to ease coordination and control among e-government providers.

The hybrid architecture applies fully centralized architecture for one-stop e-government portal. The EGA is distributed architecture to provide EGA to 1EGP. However, it also centralized a-government services under coordination of EGAP. The EGS is distributed architecture at the lowest level to form a hierarchical structure.

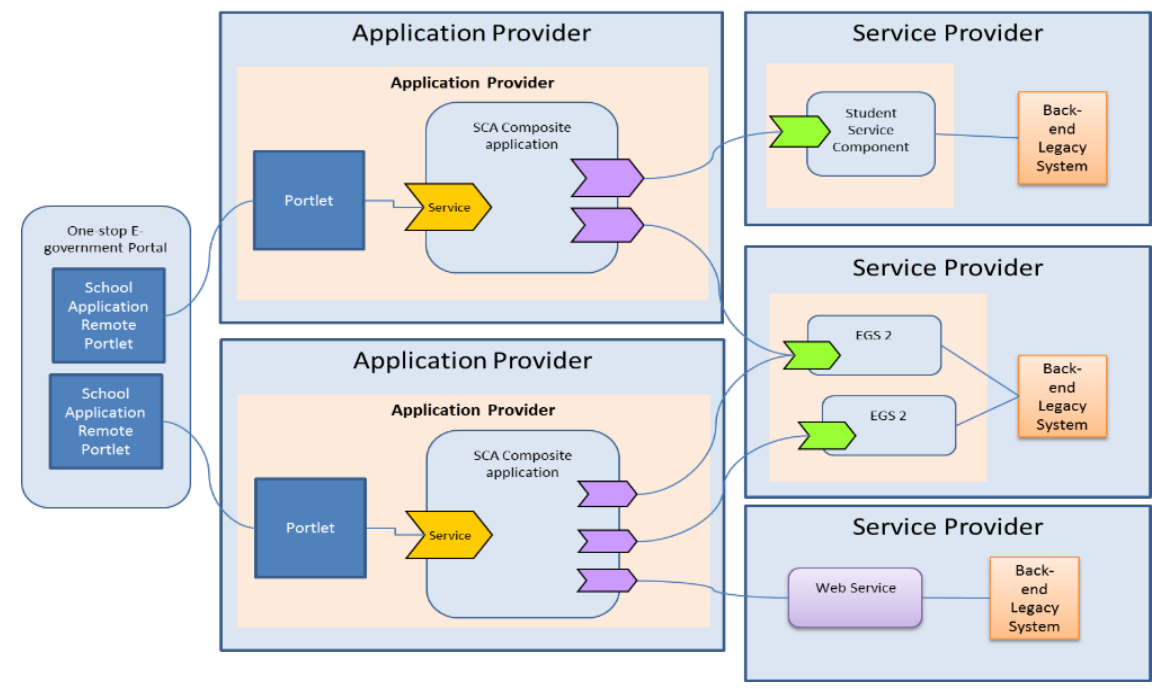

Figure 1: Integration and interoperability between One-Stop E-Government Portal and e-government

1EGP provider act as coordinator to hosts all e-government application (EGA) and hosts all EGA in a centralized 1EGP. In Malaysia, Malaysian Administrative Modernisation and Management Planning Unit (MAMPU) is responsible to provide 1EGP. All EGA can be accessed and used by users from 1EGP. All transaction can be done in the 1EGP.

EGAP is all ministry level in public administration structure that act to provide EGA to be hosted in 1EGP. EGA is complete e-government application develop from integration and interoperability with EGS.

EGS is shared e-government services which provided by department level in public administration hierarchy. The department act as E-Government Service Provider (EGSP). EGAP have to coordinate all EGSP based on their role and responsibility to ensure public services in public hierarchical structure can shared and reused by any EGAP to develop EGA. The architectural approach fairly segregated the development, maintenance and work load to distributed e-government application and service providers.

\section{THE PROTOTYPE AND ITS EVALUATION}

This study verifies an existing one-stop e-government portal of Malaysia, MyGovernment ("MyGOV - The Government of Malaysia's Official Portal," n.d.) using functional unit testing known as a black box testing. The testing aims to identify the level of integration between one-stop e-government portal and another egovernment system. This work uses the result to compare its integration level with the proposed architectural approach in the aspect of providing more benefits to users and e-government providers. 
Figure 2 depicts a scenario where a user accesses the school admission application from MyGovernment portal (http://www.government.gov.my). From the home page of the portal, the user needs to three pages before the portal links to the online e-government application for school admission application:

- https://eprasekolah.moe.gov.my/ for pre-school application or

- https://public.moe.gov.my/?kpm=daftarpengguna for primary school.

MyGovernment portal uses Hypertext Transfer Protocol (HTTP) hyperlink to connect to the Website.

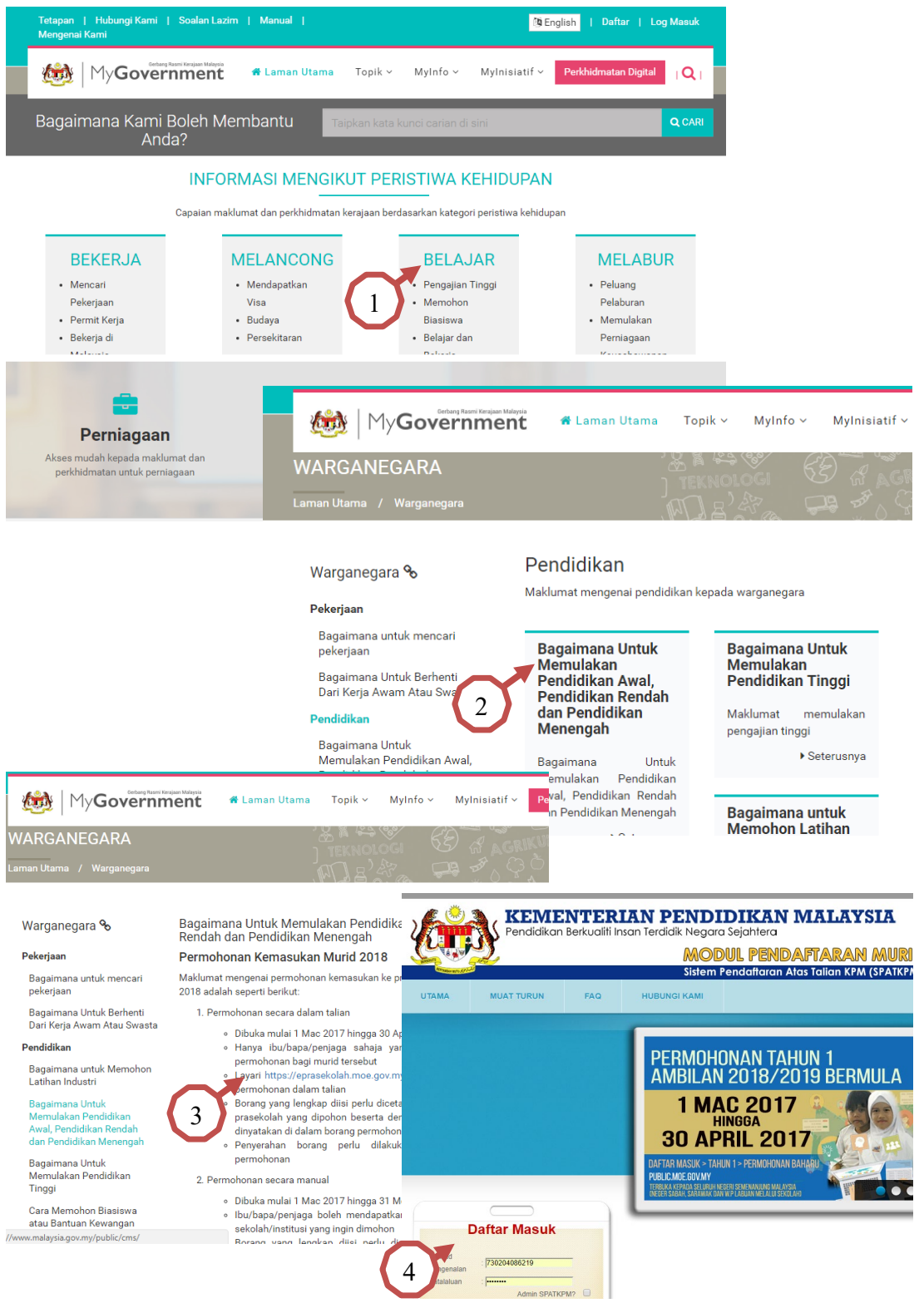

Figure 2: School admission application scenario from MyGovernment Portal

Figure 3 depicts a scenario where user accesses three e-government applications from the one-stop egovernment (1EGP) prototype. It shows that the user can access multiple e-government application (EGA) from the Homepage of the portal. Form the user's view, the application is a single system but it actually external EGA provided by E-Government Application Provider (EGAP). 
In contrast, MyGovernment portal links to different EGA in different Website. However, the user does not know how the e-government application can be accessed from the portal. On the other hand, MyGovernment portal clearly opens different e-government application using HTTP link. At the back-end the 1EGP prototype it has integration and interoperability with EGA.

An e-government application is a different system provided by the e-government application provider (EGAP) that are hosted as a remote portlet in the one-stop e-government portal. The integration between the portal and an e-government service provider uses Web Service for Remote Portlet (WSRP). The integration provides technical interoperability between 1EGP and EGA because it uses open standard WSRP 2.0 specification. EGA is a composite application that is constructed from the composition of egovernment services (EGS).

The integration between EGA and EGS uses reference through Web service JavaScript Object NotationRemote Procedure Call (JSON-RPC) and Remote Method Invocation (RMI). The implementation of the egovernment application uses Java implementation that can interoperate with external services through references. The separation of composite application and reference provides organization interoperable between EGA and EGS. 


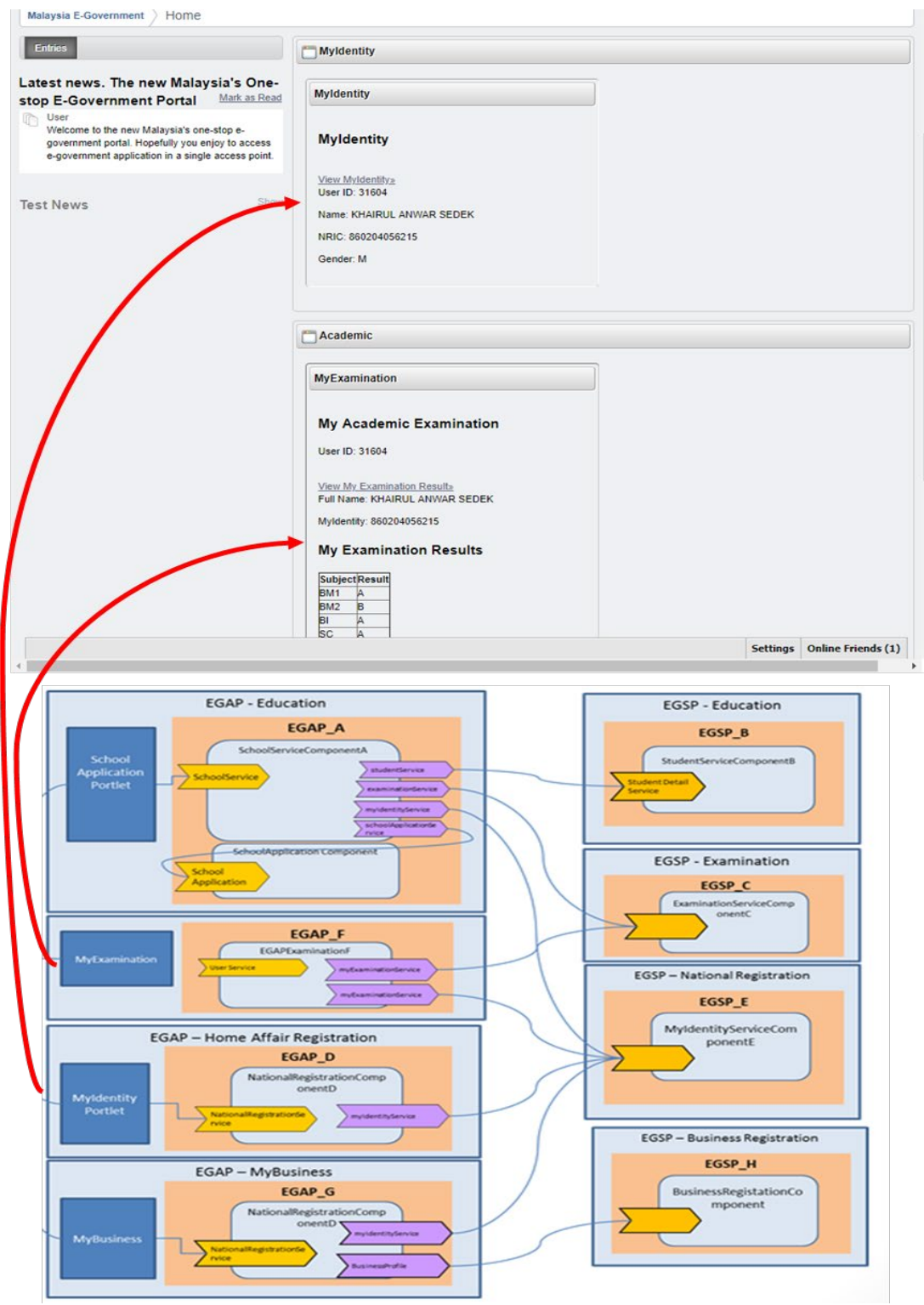

Figure 3: School admission application scenario from the prototype of a One-Stop E-Government Portal using the proposed architecture

Table 1 presents the comparison between MyGovernment portal and the prototype of one-stop egovernment portal using the proposed architecture. MyGovernment is different from the prototype in a number of aspects.

Table 1: Comparison between MyGovernment portal and the prototype of one-stop e-government portal using the proposed architecture

\begin{tabular}{ccc}
\hline Compared Item & MyGovernment & $\begin{array}{c}\text { One-Stop E-Government } \\
\text { Portal Prototype }\end{array}$ \\
\hline User access method & Hyperlink & $\begin{array}{c}\text { Plug-in e-government } \\
\text { application }\end{array}$ \\
$\begin{array}{c}\text { Integration method to e- } \\
\text { government services }\end{array}$ & HTTP Hyperlink & $\begin{array}{c}\text { Web Service Remote } \\
\text { Portlet (WSRP) }\end{array}$
\end{tabular}


How user open and complete egovernment services
Open, access, and complete e-government services through external e-government Web site or application
Open, access, and

complete e-government services through egovernment application inside the portal

MyGovernment portal uses hyperlink to connect user to the e-government services using Hypertext Transfer Protocol (HTTP) hyperlink as integration method. By contrast, the prototype is plug-in egovernment application using Web Service Remote Portlet (WSRP). On the aspect, MyGovernment portal's user have to start and finish a transaction in e-government services in different Web application site. In contrast, the prototype user can start and finish any e-government application in the portal without leaving the portal to other Web application site. It is clear that, the prototype delivers more benefit to user which can provide user to open and complete any e-government application transaction in the same portal using WSRP as plug-in e-government application.

The prototype using the proposed approach provides a single access point as compared to MyGovernment portal in which users can find, access and complete e-government service from a single portal. The implementation shows that the prototype has successfully being evaluated as the proof of concept for the proposed e-government integration and interoperability architecture.

\section{Discussion}

The verification of the proposed architectural approach is based on the development of a prototype for the integration of a one-stop e-government portal, e-government applications, and e-government services. It demonstrates the integration and interoperability of a one-stop e-government portal based on the proposed architectural approach in a prototype development that is based-on a real scenario. The scenario is the implementation of the prototype for an Online School Admission Application System. The prototype development provides detail development method based on the hierarchical e-government architecture as an example of implementation. It provides guideline and example for the real development or experiment for different architectural approach and newer or enhanced technique. The implementation suggests restructuring three main components of e-government in hierarchical structure to ease to control the roles of e-government providers and their responsibilities according to public administration structure.

The implementation compares the one-stop e-government portal prototype versus MyGovernment, Malaysia's one-stop e-government portal. The comparison is conducted in similar usage scenario, an application of school admission through both portals. The study evaluates both portals and use the portals to access school admission application and assess how both portals provide the application. The results show that the prototype provides better service provision to access and complete application transaction through one access point. In contrast, MyGovernment portal only provides hyperlink to direct users to different e-government application systems.

Compared to other architecture, our study develops the architectural approach based on architectural principles that address three main problems related to one-stop e-government portal integration and interoperability, architectural structure, service sharing and reuse. Other works are more focussed on Reference Architecture for Government Data Interoperability (Cenci, Fillottrani, \& Ardenghi, 2017), Enterprise Architecture for e-Government (Agarwal, Thakur, \& Chauhan, 2017), Cloud Service Architecture (Aubakirov \& Nikulchev, 2016; Mosa, El-Bakry, El-Razek, \& Hasan, 2016) middleware for integration (Chaabane et al., 2015), and SOA e-government for cross-border information sharing (Paul, 2015; Paul \& Paul, 2014). The architectural principles provide the guidelines to ensure the architecture fulfils the main role of a one-stop e-government portal. 


\section{CONCLUSION}

The study contributes to the integration and interoperability for a one-stop e-government portal using hierarchical architecture. In order to provide an effective one-stop e-government portal, it requires effective integration and interoperability of one-stop e-government portal, e-government application providers by using an architectural approach based on public administration organizational structure. The architectural approach provides clear organizational structure of e-government components and elements and the relationships. Thus, its eases the control of e-government providers based on their roles as defined in the organization structure.

The implementation in this study is limited to a small prototype of a one-stop e-government portal. Although the result is based on a small implementation, it suggests the possibility for various integration platforms and scenarios between e-government applications and service providers. Thus, it could lead to more possibilities in solving related integration and interoperability issues in future work.

\section{REFERENCES}

Agarwal, R., Thakur, V., \& Chauhan, R. (2017). Enterprise Architecture for E-Government. In Proceedings of the 10th International Conference on Theory and Practice of Electronic Governance (pp. 47-55). New York, NY, USA: ACM. https://doi.org/10.1145/3047273.3047330

Ahuja, A., \& Ahuja, N. (2008). Why Enterprise Architecture Is Must for One-Stop E-Government? In Emerging Technologies in E-Government. New Delhi: GIFT Publishing.

As'ad, A. M., Khazaei, B., Akhgar, B., \& Alqatawna, J. (2016). Importance of Service Integration in EGovernment Implementations. In 2016 7th International Conference on Information and Communication Systems (ICICS) (pp. 56-61). Irbid, Jordan: IEEE. https://doi.org/10.1109/IACS.2016.7476086

Aubakirov, M., \& Nikulchev, E. (2016). Development of System Architecture for E-Government Cloud Platforms. International Journal of Advanced Computer Science and Applications, 7(2). https://doi.org/10.14569/IJACSA.2016.070235

Beer, D., Kunis, R., \& Runger, G. (2006). A Component Based Software Architecture for E-Government Applications. In Availability, Reliability and Security, 2006. ARES 2006. The First International Conference on (pp. 8-pp). Retrieved from

http://ieeexplore.ieee.org/xpls/abs_all.jsp?arnumber $=1625417$

Cellary, W., \& Strykowski, S. (2009). E-Government Based on Cloud Computing and Service-Oriented Architecture. In Proceedings of the 3rd International Conference on Theory and Practice of Electronic Governance (pp. 5-10). New York, NY, USA: ACM. https://doi.org/10.1145/1693042.1693045

Chaabane, E. K., Hadouaj, S., \& Ghédira, K. (2015). Distributed Government Architecture Based on Intelligent Agents and Web Services. In 2015 IEEE/WIC/ACM International Conference on Web Intelligence and Intelligent Agent Technology (WI-IAT) (Vol. 1, pp. 41-44). https://doi.org/10.1109/WI-IAT.2015.84 
Contenti, M., Mecella, M., Termini, A., \& Baldoni, R. (2005). A Distributed Architecture for Supporting e-Government Cooperative Processes. In M. Böhlen, J. Gamper, W. Polasek, \& M. A. Wimmer (Eds.), E-Government: Towards Electronic Democracy (pp. 181-192). Springer Berlin Heidelberg. Retrieved from http://link.springer.com/chapter/10.1007/978-3-540-32257-3_17

De Angelis, F. (2009). Interoperability in e-Government Services. Universita di Camerino, Itali. Retrieved from http://193.204.12.15/139/

Dutta, A., Devi, M. S., \& Arora, M. (2017). Online Census-based Information Sharing for Delivery of eGovernance Services. In Proceedings of the Special Collection on eGovernment Innovations in India (pp. 45-51). New York, NY, USA: ACM. https://doi.org/10.1145/3055219.3055226

Ebrahim, Z., \& Irani, Z. (2005). E-Government Adoption: Architecture and Barriers. Business Process Management Journal, 11(5), 589-611.

Fath-Allah, A., Cheikhi, L., Al-Qutaish, R. E., \& Idri, A. (2014). E-Government Portals Best Practices: A Comprehensive Survey. Electronic Government, an International Journal, 11(1/2), 101-132. https://doi.org/10.1504/EG.2014.063316

Fishenden, J., \& Thompson, M. (2013). Digital Government, Open Architecture, and Innovation: Why Public Sector IT Will Never Be the Same Again. Journal of Public Administration Research and Theory, 23(4), 977-1004. https://doi.org/10.1093/jopart/mus022

Goldkuhl, G. (2008). The Challenges of Interoperability in E-Government: Towards a Conceptual Refinement. In Proceedings pre-ICIS 2008 SIG eGovernment Workshop.

Gong, Y., \& Janssen, M. (2013). An Interoperable Architecture and Principles for Implementing Strategy and Policy in Operational Processes. Computers in Industry. https://doi.org/10.1016/j.compind.2013.06.018

Lankhorst, M. M., \& Derks, W. L. . (2007). Towards A Service-Oriented Architecture for Demand-Driven e Government. In Enterprise Distributed Object Computing Conference, 2007. EDOC 2007. 11th IEEE International (pp. 214-214). IEEE. https://doi.org/10.1109/EDOC.2007.27

Laws, S., Combellack, M., Feng, R., Mahbod, H., \& Nash, S. (2011). Tuscany SCA in Action. Stanford, CT: Manning. Retrieved from http://manning.com/laws/Sample-Ch-01.pdf

Markande, K. (2011). One-Stop Services: A Conceptual Approach using EA Reference Framework. SETLabs Briefings, 9(2), 23.

Mosa, A., El-Bakry, H. M., El-Razek, S. M. A., \& Hasan, S. Q. (2016). A Proposed E-Government Framework Based on Cloud Service Architecture. International Journal of Electronics and Information Engineering, 5(2), 93-104.

Novakouski, M., \& Lewis, G. A. (2012). Interoperability in the E-Government Context. SEI, Carnegie Mellon University. Retrieved from http://192.58.107.83/reports/11tn014.pdf

Paul, A. (2015). Integrated Public Service Delivery in Agile e-Government System through Service Oriented Enterprise Model in the Context of India. Innovation and the Public Sector, 295. 
Paul, A., \& Paul, V. (2014). A Framework for e-Government Interoperability in Indian Perspective. International Journal of Computer Information Systems and Industrial Management Applications, $6,582-591$.

Salhofer, P., \& Ferbas, D. (2007). A Business Process Engine Based E-Government Platform. In Second International Conference on Internet and Web Applications and Services, 2007. ICIW '07 (pp. 5454). https://doi.org/10.1109/ICIW.2007.1

Tambouris, E. (2001). An Integrated Platform for Realising Online One-Stop Government: The eGOV Project. In Database and Expert Systems Applications, International Workshop on (Vol. 0, p. 0359). Los Alamitos, CA, USA: IEEE Computer Society. http://doi.ieeecomputersociety.org/10.1109/DEXA.2001.953087

Tambouris, E., Archetypon, S. A., \& Wimmer, G. M. (2004). Online One-Stop Government: A Single Point of Access to Public Services. Electronic Government Strategies and Implementation, 115.

The Malaysian Public Sector ICT Strategic Plan 2016 - 2020. (2016). Malaysia Administrative Modernisation and Management Planning Unit ( MAMPU). Retrieved from http://www.mampu.gov.my/images/agensikerajaan/perkhidmatan/The-Malaysian-Public-SectorICT-Strategic-Plan-2016_2020.pdf

UN. (2012). United Nations E-Government Survey 2012: E-Government for the People - United Nations Department of Economic and Social Affairs. United Nations. Retrieved from http://www.un.org/en/development/desa/publications/connecting-governments-to-citizens.html

Verginadis, G., Gouvas, P., \& Mentzas, G. (2005). An Hybrid Intermediation Architectural Approach for Integrating Cross-Organizational Services. In R. Meersman, Z. Tari, \& P. Herrero (Eds.), On the Move to Meaningful Internet Systems 2005: OTM 2005 Workshops (pp. 452-460). Springer Berlin Heidelberg. Retrieved from http://link.springer.com.ezaccess.library.uitm.edu.my/chapter/10.1007/11575863_65

Votis, K., Alexakos, C., Vassiliadis, B., \& Likothanassis, S. (2008). An ontologically principled serviceoriented architecture for managing distributed e-government nodes. Journal of Network and Computer Applications, 31(2), 131-148. https://doi.org/16/j.jnca.2006.03.006

Widodo, A. P. (2010). Enterprise Architecture Model untuk Aplikasi Government. Jurnal Masyarakat Informatika, 1(1), 23-30.

Widodo, A. P., Istiyanto, J. E., Wardoyo, R., \& Santoso, P. (2013). E-Government Interoperability Framework Based on a Real Time Architecture. Retrieved from http://citeseerx.ist.psu.edu/viewdoc/summary?doi=10.1.1.697.8363

Wimmer, M. A. (2002). Integrated Service Modelling for Online One-stop Government. Electronic Markets, 12(3), 149-156. https://doi.org/10.1080/101967802320245910

Yan, P., \& Guo, J. (2010). Researching and Designing the Architecture of E-government Based on SOA. In 2010 International Conference on E-Business and E-Government (ICEE) (pp. 512-515). IEEE. https://doi.org/10.1109/ICEE.2010.137 